\title{
EL DERECHO PENAL SIMBÓLICO Y LA INEFICACIA DEL ESTADO DE EMERGENCIA CONSTITUCIONAL PARA COMBATIR LA CRIMINALIDAD
}

\author{
SYMBOLIC INEFFECTIVE CRIMINAL LAW AND STATE \\ CONSTITUTIONAL EMERGENCY TO FIGHT CRIME
}

\author{
Lizet Zavala Van Oordt \\ Abogada \\ Universidad de San Martín de Porres \\ ljzv@hotmail.com
}

Perú

\section{SUMARIO}

- Introducción

- El derecho penal simbólico

- El estado de emergencia constitucional

- Análisis de los índices de criminalidad en la Provincia Constitucional del Callao

- La política criminológica en un Estado democrático y de derecho

- Conclusiones

- Referencias

\section{RESUMEN}

En este artículo, la autora analiza la esterilidad del denominado derecho penal simbólico y la ineficacia de una de sus expresiones recurrentes en nuestra realidad para combatir la criminalidad, como es la declaración de estado de emergencia constitucional, a propósito de la reciente experiencia vivida en la Provincia Constitucional del Callao. Asimismo, subraya el mal uso de una política penal represiva, vindicativa y carente de razonabilidad, con la finalidad de reafirmar concluyentemente el deber ético y la obligación constitucional que tiene todo Estado democrático y de derecho de diseñar y aplicar una política criminológica eficaz para controlar y reducir la criminalidad, respetando la dignidad de la persona humana.

\section{PALABRAS CLAVE}

Derecho penal simbólico, estado de emergencia constitucional, política criminológica, Estado democrático y de derecho.

\begin{abstract}
In this article the author analyzes the sterility of so-called Criminal Law Symbolic and the ineffectiveness of one of its recurring expressions in our reality, as is the declaration of a state of constitutional emergency, to fight crime, apropos of the recent experience lived in the Province Constitutional Callao, and highlights the misuse of a repressive, vindictive and devoid of reasonable criminal policy; in order to conclusively reaffirm the ethical duty and constitutional obligation of every democratic state and right criminological design and implement a policy respecting the dignity of the human person is effective to control and reduce crime.
\end{abstract}

\section{KEYWORDS}

Criminal law symbolic, democratic constitutional state of emergency, criminological policy, democratic and right state

\section{INTRODUCCIÓN}

El 4 de diciembre de 2015, el presidente de la República, el presidente del Consejo de Ministros y los ministros de Estado en las carteras del Interior, de Justicia y de Derechos Humanos, expidieron el Decreto Supremo N. ${ }^{\circ}$ 083-2015-PCM publicado insólitamente ${ }^{1}$ ese mismo día en el diario oficial El Peruano.

\footnotetext{
1 Es curioso y extraño que la publicación de una norma legal y este tengan la misma fecha. Por lo general, media cuando menos un dia entre la norma y su publicación por razones operativas y horarias de edición.
} 
En este se declaró por el término ${ }^{2}$ de cuarenta y cinco días calendario, computado a partir de la fecha de publicación, el estado de emergencia en la Provincia Constitucional del Callao. Se dispuso que la Policía Nacional mantenga el control del orden interno y suspendieron los derechos constitucionales relativos a la libertad y seguridad personales y la inviolabilidad de domicilio, comprendidos en los incisos 9 y 24 apartado f) del artículo $2^{\circ}$ de la Constitución Política del Perú.

A partir de ese momento y hasta el 30 de agosto de $2016^{3}$, se prorrogaron sucesivamente las declaraciones del estado de emergencia en el Callao a través de sendos decretos supremos, con lo cual se llegó al absurdo de suspender durante ocho meses y veintiséis días los mencionados derechos constitucionales.

Esta situación, por demás extravagante jurídicamente, abarcó en el tiempo una parte de cada uno de dos gobiernos, el del expresidente Ollanta Humala Tasso y el del actual presidente, Pedro Kuczynski Godard. Más allá de la anormalidad constitucional de la medida en sí misma en un Estado democrático y de derecho, ella invita a reflexionar si la problemática que le dio origen (esto es, el incremento de la criminalidad en dicha circunscripción territorial) justificaba adoptar una disposición tan extrema, durante tanto tiempo, restrictiva de esos derechos fundamentales, y si los baremos fácticos y jurídicos expresados en la parte considerativa de los decretos supremos resultaban ciertos y, de ser así, significativos para afectar la normalidad constitucional en la primera provincia del país.

Ese es el objetivo de este artículo: examinar y analizar la problemática expuesta como sustento de las declaraciones de los estados de emergencia sucesivos y su razonabilidad política y criminológica. Esto permitirá corroborar la inoperancia e inutilidad de dicho régimen y reconocer la ausencia de medidas criminológicas eficaces en nuestro país. Además, posibilitará ratificar el mal uso de la política penal como modalidad repetida de un

2 Técnicamente debió decirse plazo, porque es el periodo durante el cual se produce un efecto jurídico o se debe hacer una cosa. En cambio, el término es el momento en que concluye el plazo.

3 El Decreto Supremo $N^{\circ}$ 056-2016-PCM de 29 de julio de 2016, publicado el 30 de julio del mismo año en el diario oficial El Peruano, decretó la última prórroga del estado de emergencia, por treinta dias calendario, a partir del 31 del citado mes y año. derecho penal simbólico que expresa el ejercicio arbitrario del ius puniendi estatal y afecta gravemente la dignidad de la persona humana.

En ese sentido, el artículo aborda y desarrolla sucesivamente el significado y efectos perniciosos del simbolismo penal, la verdadera y no solo técnica anormalidad de un estado de emergencia constitucional cuando se emplea sin sustento razonable. Asimismo, analiza los índices de criminalidad en la Provincia Constitucional del Callao durante los estados de emergencia y sostiene cómo debe ser la política criminológica en un Estado democrático y de derecho. Esto con el propósito de arribar a conclusiones asentadas en la criminología y formular recomendaciones para evitar nuevamente esta clase de medidas, que únicamente persiguen gobernar a través del crimen.

\section{EL DERECHO PENAL SIMBÓLICO}

La política es la lucha por el poder y en su ejercicio se construyen y salvaguardan símbolos porque tienen un potencial de sensibilidad conmovedora con el que es posible operar, maniobrar y conducir acciones precisamente para mantener el poder. La relación entre política y derecho no está exenta de impurezas en nuestro medio. Cuando estas se presentan, lamentablemente la desfavorecen, pues la política «se las arregla» para transmitir al derecho penal sus intereses, que son (y deben ser) ajenos al ámbito técnico y equitativo de la normativización y operatividad de los órganos de administración de justicia $y$, en el campo penal, de la regulación y actuación de las agencias de control punitivo.

Por ejemplo, la representación nacional sanciona leyes penales simbólicas desde el Congreso, porque existe sistémicamente una pretensión política de prohibir sin que, necesariamente, se den los contextos, situaciones y escenarios para que dichas normas cumplan con su verdadera finalidad. Tal situación permite apreciar que la función simbólica de nuestro derecho penal es extensa y que se le atribuye un papel significativo. Es el caso de las penas en general y de la pena privativa de libertad en particular; de la neocriminalización y la sobrecriminalización; de las leyes penales medioambientales; las de punición de la criminalidad organizada; las de delitoseconómicos; las de privación debeneficios penitenciarios; las de imprescriptibilidad de 
algunos delitos. Estas y otras tantas se promulgan en estos tiempos con periodicidad y frecuencia asombrosa para mantener y fomentar la confianza y lealtad en el derecho, para decir que el sistema es invulnerable y predicar la libertad e igualdad en todas sus manifestaciones, como por ejemplo, en la ley y su aplicación. Lo cierto es que constituyen procesos comunicativos de intromisiones meramente simbólicas, por cuanto no sirven para prevenir, controlar ni reducir la criminalidad, pero aparentan proporcionar seguridad y tranquilidad.

En todos estos casos, se aprecia una instrumentalización del derecho penal para contraponer una situación real y una situación aparente, el fondo y la forma, lo notorio y lo sabido, lo que se dice querer lograr y lo que se aplica; es decir, hay simbolismo cuando existe engaño e ilusión. ¿Acaso las normas penales están en condiciones de hacer los cambios sociales que se requieren para que la criminalidad disminuya?

El derecho penal es una expresión política de poder. Pero no solamente es cuestión de poder e intereses, sino que también comprende el suministro y la protección de símbolos que tienen potencial emotivo y manipulador, con lo cual el poder político desarrolla la capacidad de generar ficciones y mitos. A tal efecto, despliega todo su arsenal penal simbólico, como leyes que declaran líricamente valores que en la praxis, y por otras vías, el mismo Estado no respeta; leyes de apelación moral, que pretenden infructuosamente crear conciencia a determinadas personas que gozan de posiciones relevantes; leyes que sirven de coartada, leyes de crisis, leyes de contestaciones sustitutas para calmar a la opinión pública; y leyes de compromiso, que pretende satisfacer la necesidad del gobierno de actuar ante la criminalidad aparente.

El caso de la declaración y prórroga del estado de emergencia para fortalecer la lucha contra la criminalidad, caería dentro de la categoría de normas de excusa y justificación frente a una situación que no es grave, como lo dicen las estadísticas, o que ha sido creada o reforzada mediante el discurso político y de los medios de comunicación.

La noción de símbolo en el derecho penal constituye así un mecanismo o dispositivo de engaño, de inexistente efectividad y eficacia, como cualidad objetiva de la norma. Por ello, resulta ser meramente instrumental, ya que las funciones ocultas, las que obedecen al fin falaz, prevalecen sobre las reales, logrando otros objetivos distintos a los que debe perseguir una norma penal democrática.

En consecuencia, el simbolismo de la ley penal pone de relieve la crisis en la que está sumido el derecho penal, por estar encauzado a las consecuencias de la conducta desviada tipificada como delito, mas no a su prevención, lo cual complica y agrava su deslegitimación, pues no es suficiente que la ley penal sea formalmente válida. No obstante, existen algunas leyes que contradicen la jerarquía constitucional y que fundamentalmente deben ser eficaces en el logro de los objetivos del sistema penal; esto es, un control razonable de la criminalidad y una verdadera resocialización del penado.

\section{EL ESTADO DE EMERGENCIA CONSTITUCIONAL}

De acuerdo con el maestro constitucionalista Alfredo Quispe en su ensayo Régimen de excepción, una Constitución Política prevé un orden jurídico político determinado, en el que sus diversas instituciones pueden operar con eficacia en el marco de una situación de normalidad; sin embargo, la realidad demuestra que el orden previsto en la norma no siempre es predecible o, lo que es lo mismo, es necesario prever situaciones de anormalidad.

Por dicha razón absolutamente empírica, es indispensable una fórmula para superar una eventualidad que afecte profundamente la vida social y pueda conducirla hacia críticos estados irreversibles de caos, anarquía e ingobernabilidad, con la finalidad de vivir jurídicamente. En semejante coyuntura, la Constitución debe ceder y suspender parcialmente su vigencia a fin de que los objetivos de seguridad interna y externa sean logrados.

La hipotética coyuntura puede presentarse cuando existan indicios razonables $o$ hechos concretos que hagan suponer graves perjuicios para la república. El régimen de excepción constitucional denominado estado de emergencia procederá cuando se perturbe la paz o el orden interno, de catástrofe o de graves circunstancias para el país. En tanto, el régimen de excepción denominado estado 
de sitio procederá en caso de invasión, guerra exterior, guerra civil o peligro inminente que se produzca. La diferencia no solo es en las causas de hecho que motivan ambos regímenes, sino también en las consecuencias, pues los derechos fundamentales restringidos varían en uno y otro caso.

Pero centrémonos en las causas. Si se las lee detenidamente, veremos que hay similitud, pues ¿qué es la perturbación de la paz o graves circunstancias que afecten la vida de la Nación (causas del estado de emergencia) comparado con los casos de invasión, guerra civil o peligro que se produzcan (causas del Estado de sitio)? ¿No es acaso exactamente igual, pues en estos casos se configuran a su vez aquellos? Si a este análisis agregamos que las consecuencias en ambos estados son perjudiciales para la ciudadanía porque afectan derechos fundamentales, entonces concluimos en que el gobierno en ejercicio razonable de su potestad deberá decidir, en un curso de acción política, cuál de las dos medidas es más racional, lo cual tendrá necesariamente como sustento el análisis profundo de la situación de hecho.

A mayor abundamiento, son características esenciales de los estados de excepción el ser extraordinarios y temporales. En el caso materia de estudio, la medida dispuesta por el presidente de la República no era ni extraordinaria ni fue transitoria. En efecto, el índice de criminalidad ya era alto, según lo muestra la estadística del 2015 que se glosa en el parágrafo IV. La medida fue prorrogada varias veces durante nueve meses, lo que sin lugar a dudas cuestiona su transitoriedad, pues existió prolongada permanencia de una norma excepcional.

Ahora bien, en el caso de la declaratoria, el leiv motiv fue el fortalecimiento de la lucha contra la criminalidad en todas sus modalidades, según lo expuesto en la parte considerativa del decreto supremo que estableció el estado de emergencia. En los casos de la prórroga de dicho estado prolongado por más de nueve meses, la causa eficiente fue la consolidación (i?) de la lucha contra la criminalidad, según lo expuesto en la parte considerativa de los decretos supremos de prórroga. Entonces, cabe preguntarse si el primero era un motivo razonable o si podían dictarse medidas de política criminológica en vez de afectar los derechos humanos de la ciudadanía, y luego preguntarse si el motivo de las sucesivas prórrogas era real, pues está contradicho por las estadísticas. Así, pues, concluiremos que se trató de una norma netamente simbólica, instrumental e ineficaz, que no logró absolutamente nada de lo que una norma jurídica de este tipo debe aspirar a lograr. Esto ya que, durante la vigencia de dicho régimen de excepción constitucional, la criminalidad no disminuyó de acuerdo con las estadísticas.

Entonces, ¿es democrático que el gobierno tenga esta actitud política y no escatime normar la restricción de los derechos fundamentales de las personas para pretender combatir la criminalidad, en vez de valerse de la criminología para diseñar, planificar, programar y proyectar una política criminológica eficaz, digna de un Estado democrático y de derecho? Evidentemente no, porque el Estado no debe conducirse de manera improvisada o facilista, y porque es indispensable que dicte normas razonables con el apoyo de la disciplina científica pertinente para superar las situaciones que le impiden cumplir con sus fines esenciales, uno de los cuales es la seguridad integral.

Esta situación ocurre en pleno siglo XXI, en el que los derechos y las libertades humanas han alcanzado un sitial preponderante teóricamente; sin embargo, vemos que el poder busca mantenerse mediante medidas políticas de dominación y control verticales, injustificadas y discriminatorias, que tienen un efecto placebo en la sociedad, la cual no se da cuenta que está siendo gobernada a través del crimen.

Esta situación neo moderna, en la que la ley queda suspendida en un determinado espacio territorial, se asemeja al campo de concentración, que era un permanente estado de excepción en donde la persona era segregada de la sociedad por el propio Estado.

Es un hecho que, actualmente, el estado de excepción ha pasado de ser un mecanismo provisional para situaciones de extremo peligro, a un instrumento normal de gobierno. Ya no es la excusa de la seguridad frente al terrorismo, sino frente a la criminalidad, con lo cual la excepción se ha convertido en norma. Desde el enfoque estatal, que vigila y controla, decreta estados de excepción y detiene al ciudadano, éste ha devenido en un terrorista o criminal potencial. 
El análisis desde la ciencia política pone de manifiesto que existe una fractura de la legitimidad del poder, pues la situación antes descrita se da en muchos Estados, los que presentan legalidad porque se votan las leyes y dictan normas de acuerdo con el procedimiento formalmente establecido, pero no se cumplen porque no tienen legitimidad, esto es, no se han originado en el interés general ni son justas, razón por la cual al no ser obedecidas por ser ajenas y extrañas a la voluntad general, resultan siendo ineficaces,

Por ello, precisamente, los poderes e instituciones públicas tienen hoy en día los índices más bajos de credibilidad, pues la población no confía en sus autoridades ${ }^{4}$.

Se puede visualizar aquí la necesaria existencia de una íntima relación entre ética y política. La ética es el arte de vivir y la política el arte de convivir, de modo tal que el plano individual en que se desenvuelve la primera se debe proyectar al plano social en el que se desarrolla la segunda.

Sin embargo, la falta de credibilidad hace que las personas se despoliticen y limiten a ejercitar su derecho de elección porque a alguien hay que elegir para que se encargue de la conducción del estado, auto excluyéndose de la vida política de la nación, la cual queda en manos de una clase política de advenedizos, pillos y prestidigitadores que dirigen el país en función de intereses particulares, marginando y relegando a grupos sociales desfavorecidos y vulnerables, a quienes se les estigmatiza y etiqueta, por lo que son los destinatarios "naturales" de los estados de excepción.

A decir de Agamben, G. (2003) cada uno de estos ciudadanos es el nuevo homo sacer del

4 El Congreso de la República continúa siendo la institución que más desconfianza genera en la ciudadanía. Sus constantes escándalos y su poca eficiencia le siguen pasando factura. Según la última encuesta de El Comercio hecha por Ipsos Perú, el $84 \%$ de la población no confia en ese poder del Estado. Los partidos políticos se encuentran casi en la misma situación. La desconfianza hacia ellos alcanza un nada envidiable $82 \%$, lo cual evidencia el poco interés que despiertan en la población desde hace muchos años. Igualmente el Poder Judicial continúa desacreditado. Sus polémicos fallos y su lentitud hacen que un $79 \%$ no le tenga confianza. El Poder Ejecutivo también está entre las instituciones menos confiables. E1 $73 \%$ de la gente no confia en él, según la encuesta realizada en Lima. Recuperado de http://elcomercio.pe/politica/actualidad/tremendadesconfianza-opinion-ciudadana-sobre-institucionesnoticia- 1842421
Derecho Romano, aquel hombre a quien se consideraba sagrado (en poder de los dioses) pero al mismo tiempo podía dársele muerte sin que esto constituyera un delito. "La vida insacrificable y a la que, sin embargo, puede darse muerte, es la vida sagrada". ¿Cómo se le da muerte? No solo con la criminalidad predatoria, sino principalmente con la criminalidad económica y política organizada, que afecta gravemente los derechos humanos al detraer importantes recursos económicos del presupuesto estatal debido a los sobre costos de las obras públicas y servicios que el estado contrata merced a una arraigada corrupción institucional. Así, la soberanía del estado es capaz de suspender la ley decretando el estado de excepción.

En el Derecho Romano la vida se presentaba en relación con el poder del pater familia de dar muerte al hijo varón, lo que significaba que era la contrapartida de un poder que amenazaba con la muerte. El estado de excepción decidido y decretado por el estado, es la reminiscencia del pater familia romano?

Veamos cómo los ciudadanos pertenecientes a los grupos sociales desfavorecidos $\mathrm{y}$ marginales tienen una forma de vida real que es supervivencia, que angustiosamente hacen frente a la violencia, dolencias extremas y desventuras cotidianas. Nos preguntamos entonces si esos ciudadanos tienen derechos diferentes a los del hombre. Si hay una categoría de derechos del ciudadano y otra categoría de derechos del ciudadano, como parece sugerir el mismo título de la Declaración de los Derechos del Hombre y del Ciudadano.

Consideramos que ello no es así. El nacimiento es portador de soberanía y, por ello, el hombre es al mismo tiempo ciudadano, por lo que no debe estar en una situación de indefensión frente al estado.

Actualmente, el estado de excepción es utilizado por los gobiernos con impudicia, lo que revela que la política padece un prolongado oscurecimiento, dado que el estado-nación y los derechos humanos son insuficientes para garantizar bienestar general y seguridad integral, de ahí que es imprescindible reconocer que entre el Derecho y la vida la acción política es un espacio para la acción humana benefactora. 


\section{ANÁLISIS DE LOS ÍNDICES DE CRIMINALIDAD EN LA PROVINCIA CONSTITUCIONAL DEL CALLAO}

Las estadísticas de seguridad ciudadana correspondientes al periodo enero-junio de 2015, que figuran en el informe técnico del Instituto Nacional de Estadística e Informática (INEI), permiten observar en el cuadro 71 de victimización según departamento, que la Provincia Constitucional del Callao registraba una tasa de $29,7 \%$ y en el periodo enero-junio de 2016 registraba una tasa de $35,8 \%$. Es decir, antes de decretarse el estado de emergencia, la victimización era menor que al concluir, más aún, la variación porcentual entre dichos periodos fue $6,1 \%$ al alza.

Asimismo, el mencionado cuadro pone de manifiesto que los departamentos con mayores porcentajes de población víctima de algún hecho delictivo en dicho periodo eran Cusco con $47,7 \%$, Madre de Dios con 40,1\%, Tacna con $37,8 \%$, Junín con $37,4 \%$ y Huancavelica con 36,4 \%, todos ellos por encima del Callao y, sin embargo, no fueron objeto de declaratoria de estado de emergencia. Sobre la tasa de víctimas por tipo de hecho delictivo según departamento en el periodo enero-junio de 2016, el cuadro de dicho informe técnico del INEI indica que el robo de dinero, cartera o celular en el Callao era de $17,7 \%$, mientras que el secuestro y extorsión era de $0,6 \%{ }^{5}$.

En tanto, el cuadro 73 del mismo informe técnico del INEI sobre percepción de inseguridad según departamento, del periodo enero-junio de 2016, muestra los departamentos de Cusco con 95,7\%, Tacna con 95,1\%, Huancavelica con $94,2 \%$ y Madre de Dios y Arequipa con $93,8 \%$, como los departamentos con mayor percepción de inseguridad. El Callao aparece con $89,7 \%$ para el periodo enero-junio de 2015 y 93,7 \% para el periodo enero-junio de 2016; es decir, se incrementó la percepción de inseguridad en $4 \%$ precisamente durante el estado de emergencia.

El cuadro 74 del referido informe técnico enseña los resultados de victimización según ciudades de veinte mil habitantes a más. Así, tenemos que Cusco con 53,8 \%, Huaraz con 50,3\%,

5 Resultado referencial porque el número de casos en la muestra no es suficiente y presenta un coeficiente de variación mayor al $15 \%$. No obstante, sigue siendo menor al robo.
Huancayo con 43,5\%, Puerto Maldonado con $40,1 \%$, Tacna con $38,2 \%$ y Pasco con $37,7 \%$ están por encima del Callao con $35,8 \%$ en el periodo enero-junio de 2016. En el mismo periodo del año anterior, tal porcentaje era de $29,7 \%$ al iniciarse el estado de emergencia lo que significa que experimentó un incremento durante el estado de excepción.

De la misma manera, los principales indicadores de seguridad ciudadana del 2015, según la encuesta nacional de programas estratégicos del INEI, indica que la tasa de victimización en la población de 15 años de edad a más por departamento registra a Puno con 39,7 \%, Cusco con $38,8 \%$, Junín con $35,5 \%$, Tacna con $35,2 \%$, Lima con $34,2 \%$, Áncash con $33,4 \%$ y Huancavelica con $33 \%$, por encima del Callao con 32,4 \%; sin embargo, en aquellos departamentos no se decretó el estado de emergencia.

En los mismos indicadores del INEI, respecto a las viviendas afectadas por robo en el 2015, que es el delito más recurrente, aparece el Callao con $4,3 \%$, en el rango más bajo de cuatro niveles, que van de $3,2 \%$ a 4,3\% (primer nivel), de $5 \%$ a $7,9 \%$ (segundo nivel), de $9 \%$ a $9,3 \%$ (tercer nivel) y de $12,9 \%$ a $15,9 \%$ (cuarto nivel). No obstante, nuevamente solo en el Callao se decretó el estado de emergencia.

Por otro lado, según el Observatorio Nacional de Seguridad Ciudadana (sin fecha) en el periodo enero a setiembre de 2015, el mapa del delito que considera denuncias registradas en las comisarías de la Policía Nacional registra al distrito de San Juan de Lurigancho con la mayor cantidad de estas (8869 casos), mientras que el Callao registra 6600 casos; sin embargo, en aquel distrito no se decretó el estado de emergencia.

La Ley N. ${ }^{\circ} 27933$ crea el Sistema Nacional de Seguridad Ciudadana con el objeto de proteger el libre ejercicio de los derechos y libertades, garantizar la seguridad, paz, tranquilidad, el cumplimiento y respeto de las garantías individuales y sociales a nivel nacional. El Consejo Nacional de Seguridad Ciudadana es el máximo organismo encargado de la formulación, conducción y evaluación de las políticas de seguridad ciudadana con autonomía funcional y técnica. Entre sus funciones, elabora anualmente un informe nacional sobre seguridad ciudadana e informa a la comisión de 
El derecho penal simbólico y la ineficacia del estado de emergencia constitucional para combatir

la criminalidad

Symbolic ineffective criminal law and state constitutional emergency to fight crime

Defensa Nacional, Orden Interno e Inteligencia del Congreso de la República sobre los planes, programas y proyectos de seguridad ciudadana antes de su aprobación, y absuelve consultas sobre la materia.

De acuerdo con lo establecido por dicha ley, los comités regionales son los encargados de formular los planes, programas, proyectos y directivas de seguridad ciudadana. Están presididos por el presidente de la región e integrados por la autoridad política de mayor nivel y el jefe policial de mayor graduación, entre otros miembros. Tienen entre sus funciones estudiar y analizar los problemas de seguridad ciudadana en la región, así como formular, ejecutar, controlar y supervisar los planes, programas y proyectos.

¿Cuál es la interpretación que podemos dar a estas cifras porcentuales? En primer término, que antes y durante el estado de emergencia el Callao no era el territorio con mayor tasa de inseguridad ciudadana, pues había otros distritos y departamentos con mayor porcentaje de victimización y denuncias registradas. En segundo lugar, que correspondía al Consejo Nacional de Seguridad Ciudadana o, en todo caso, al Consejo Regional de Seguridad Ciudadana del Callao evaluar la situación de la seguridad ciudadana en dicha circunscripción a los efectos de reformular los planes, programas y proyectos correspondientes, con miras a superar cualquier riesgo que atente contra el libre ejercicio de los derechos y libertades, garantizar la seguridad, paz, tranquilidad, el cumplimiento y respeto de las garantías individuales y sociales de la población chalaca, $\mathrm{y}$, en último extremo, solicitar al gobierno central la declaración del estado de emergencia.

Pero no correspondía al director general de la Policía Nacional del Perú hacerlo máxime con fines impropios de un estado de excepción, como es fortalecer la lucha contra la delincuencia en todas sus modalidades, basándose en una solicitud del jefe de la Región Policial Callao, según es de ver de la parte considerativa de los respectivos decretos supremos. En efecto, en aquellos con los cuales se declaró y prorrogó el estado de emergencia, aparece como sustento dicha comunicación oficial de los referidos jefes policiales. No obstante, curiosamente el director general de la Policía Nacional del Perú no forma parte del Consejo Nacional de Seguridad Ciudadana, pues lo preside el ministro del Interior. Querría decir que, en estos casos de suyo graves por la trascendencia de la medida, el ministro del Interior refrendó los decretos supremos que se expidieron a solicitud de su subalterno, el jefe policial nacional, sin que interviniera el máximo organismo nacional encargado de la formulación, conducción y evaluación de las políticas de seguridad ciudadana con autonomía funcional y técnica.

Igual desvarío observamos en la competencia funcional del Consejo Regional de Seguridad Ciudadana del Callao con ocasión de la dación de estos decretos supremos de declaratoria y prórroga del estado de emergencia: Quien sustenta la petición es el jefe policial regional, que está por debajo de la autoridad política de mayor nivel en la región que también integra dicho consejo y del presidente de la región, quien lo preside, funcionarios ambos que no intervinieron en la dación de estas normas.

El hecho de que el estado de emergencia constitucional pueda ser decretado en caso de perturbación de la paz o del orden interno, según lo dispuesto por el artículo $137^{\circ}$ de la Constitución Política del Estado, no significa que, cuando dicha perturbación se deba a una situación de inseguridad específica, no se sigan los cánones correspondientes a la materia, esto es, consultar o solicitar el pronunciamiento del órgano creado especialmente para evaluar tal situación. Esto corresponde a un Estado democrático y de derecho, basado en la división de funciones y el respeto a la ley. Pero también permite observar la ausencia de una política criminológica que, como toda política, requiere de planeamiento, programación, proyección, formulación, conducción, evaluación y supervisión continuos y permanentes, con carácter integral y sistémico, de forma tal que constituya un conjunto de medidas distintas a la improvisación y la emotividad, como se verá en el parágrafo siguiente. En el caso materia de estudio, la medida no tiene congruencia con la ausencia de disposición similar en otros departamentos y distritos cuyo índice de criminalidad era más alto que el del Callao.

Cabe analizar que durante la ejecución del estado de emergencia los niveles de inseguridad se incrementaron insólitamente, lo cual es elocuente de la ineficacia de una medida política espontánea y sensiblera, sin legitimidad ni verdadera vocación criminológica. 
Por último, el aspecto relativo a la suspensión de los derechos constitucionales que conlleva el estado de emergencia, exige otra línea de análisis. De los cuatro derechos fundamentales (libertad y seguridad personales, inviolabilidad de domicilio, libertad de reunión y de tránsito) se restringieron los dos primeros, con lo cual la policía quedó facultada para ingresar a viviendas y detener a los ciudadanos sin orden judicial. Esta medida constitucional gravemente limitativa de derechos conlleva a reflexionar sobre su razonabilidad. A juzgar por los datos estadísticos glosados, ¿la seguridad ciudadana aparejaba un nivel de riesgo tan alto de perturbación de la paz o del orden interno? Si hubiera sido así, ¿por qué no se suspendieron los otros dos derechos fundamentales? ¿Por qué no se adoptó similar medida con otras zonas del territorio nacional que tenían mayor nivel de inseguridad? Consideramos que, cuando un gobierno apela al fácil expediente de suspender o restringir libertades, abjura de su raigambre democrática y desnuda su vocación punitiva, discriminatoria y de exclusión, demostrando que carece de noción respecto a lo que significa una política criminológica.

En efecto, de acuerdo con Habermas (1992, p. 259), el lenguaje cumple también una función de dominación y fuerza social. Por tanto, a través de sus formas específicas en la política o los medios de comunicación, por ejemplo, es un recurso de poder, lo cual conlleva a que aquellos grupos que tienen mayor influencia discursiva ejerzan más control sobre las mentes y acciones de los otros, como lo explica Van Dijk (1999, p. 26). El control penal, que es político, permite observar este rasgo característico, que a su vez incluye la mercantilización del discurso público, sea político o mediático. En suma, con un poco de observación, es posible darse cuenta cada día de que una cosa es la realidad fáctica y otra muy distinta es la realidad discursiva.

En materia de sociedad de masas, la historia demuestra que los procesos de industrialización, urbanización y posmodernidad han originado la fragmentación social. Consecuentemente, existe una mayor fragilidad en la sociedad actual, pues la libertad individual de la que tanto se habla esclaviza al hombre a cosas y objetos, menos a su pensamiento y voluntad, asimismo los valores éticos se han volatilizado en nombre de una libertad irrestricta y una adicción al entretenimiento banal. Ahora, la ilusión de cohesión social la brindan los medios de comunicación a cambio de control sobre los pensamientos y emociones de los miembros de la gran sociedad, quienes a fuerza de emplear cada vez menos su potencial racional debido al avance de las tecnologías de la comunicación y el pasatiempo, se vuelven capaces de asumir cómodamente todo tipo de influencias y predominios externos.

En esta línea, se advierte en el caso de la injustificada declaración y prórroga del estado de emergencia para combatir la criminalidad, cómo se utiliza la ley y el orden para construir un discurso punitivista y populista de dominación, asemejándose a una industria del conflicto, que fabrica leyes penales meramente simbólicas en serie y, ahora, novedosos productos de la línea constitucional, como es el estado de emergencia para fortalecer la lucha contra la criminalidad, aunque siempre bajo el mismo esquema de desigualdad social y selectividad subjetiva.

\section{LA POLÍTICA CRIMINOLÓGICA EN UN ESTADO DEMOCRÁTICO Y DE DERECHO}

Es objeto de la nueva criminología el control social del delito, el cual se considera un verdadero neomodelo (el paradigma del control) debido a la riqueza sociológica que comporta este núcleo de interés criminológico que obviamente no está exento de acento ideológico. Diferente era la situación de la criminología tradicional positivista, que se centró en el criminal por partir de un enfoque consensual del orden social que las normas penales encarnaban basándose en la protección de valores generales.

Las normas penales eran y son definidas, interpretadas, aplicadas y ejecutadas en función de intereses de grupo, en perjuicio de las clases vulnerables, de donde proviene la naturaleza conflictiva de dicho poder de criminalización. Esto porque el precepto formalmente abstracto de la norma se extravía al transitar por determinados tamices selectivos establecidos en la realidad por el estatus social del sindicado como imputado. Esa es la explicación más consistente de la nueva criminología respecto al hecho de que los grupos sociales más deprimidos y marginales tengan relación directamente proporcional con la elevada tasa de criminalidad. No es que los individuos de 
tales grupos abracen antivalores criminales por sí mismos. De ahí que el postulado neocriminológico sea que el control social crea el crimen y la criminalidad para mantener ad infinitum el sistema de dominación.

Como el control social es el conjunto de instituciones, estrategias y disciplinas sociales para someter al individuo al Estado, fuerza es deducir que quien tiene el poder político en este último utiliza el sistema penal y otros medios para lograr esa sumisión. Lo logra a través de la selección selectiva discriminatoria, la generación de crímenes y el etiquetamiento de criminales, así como la estigmatización individual que está aparejada al proceso penal.

Empero, el sistema de control social formal (penal) es estructuralmente limitado $\mathrm{y}$, en ese sentido, su severidad no quiere decir que sea eficaz, como su fracaso no viene dado necesariamente por el incremento de las tasas de criminalidad. Por ello, no es conveniente agravar incesantemente su firmeza, pues, como decía Jeffery citado por GarcíaPablos (1994): «Más leyes, más penas, más policías, más jueces, más cárceles, significa más presos, pero no necesariamente menos delitos» (p. 70). A ello podemos añadir más estados de emergencia por razón de supuestas cruzadas contra la criminalidad, como la que ha sido objeto de estudio. No expresa menos crímenes, sino que el Estado debe desplegar una política criminológica que hasta ahora está ausente de su política, la cual para ser eficaz debe ser preventiva.

El problema del que parece no darse cuenta el Estado - porque no tenemos aquí criminología, salvo algunos escasísimos esfuerzos aislados de carácter académico - consiste en que el sistema penal presupone la existencia del crimen, mas no visualiza sus factores etiológicos multicausales, que es dónde, cuándo y cómo se forma el problema de la cuestión criminal. Si el Estado no cuenta con información científica sobre el crimen, el criminal, la víctima y el control social, carecerá del conocimiento necesario para comprender y solucionar el problema, prevenirlo e intervenir positivamente en el transgresor a través de la política criminológica, evitando caer repetidamente en actitudes intuitivas, emocionales, subjetivas y tardías de carácter penal. Son ejemplos la producción insensata de normas simbólicas, de derecho penal del enemigo y de utilización de mecanismos constitucionales reservados para horas aciagas de la vida del Estado y no para fungir de instrumentos automáticos contra la criminalidad.

De hecho, una política penal, represiva, retributiva y vindicativa, así como extemporánea por naturaleza, no es razonable porque asume costos sociales elevados. Además, no siempre es efectiva y no llega a las raíces del problema; sin embargo, el Estado cree todavía que debe seguir castigando más y mejor el crimen, cuando la intervención debe ser subsidiaria y mínima, pues es mejor priorizar una respuesta social que un problema comunitario desde la prevención primaria, como es el crimen.

Sin duda, lo penal es siempre negativo y traumático por sus efectos, ya que agrava los conflictos. Si el crimen es un conflicto violento que se problematiza al no encontrar solución viable en los espacios previos del control social informal y la pena es un acto de violencia estatal, es fácil advertir que la ecuación violentista se agudiza y se vuelve crónica. Lo razonable es neutralizar los factores y las causas criminógenas que son de orden estructural y de diversa etiología (espacial, ambiental, social, económica, cultural, entre otras).

El Estado debe saber que el crimen no es un triste problema individual, sino una grave aflicción social, con todo lo que este término implica para su detección y neutralización. En este marco epistemológico, la sanción al infractor no extingue todas las esperanzas que la sociedad tiene a raíz de la cuestión criminal, por lo que existe la necesidad de reconocer como deberes del Estado la prevención del crimen, la resocialización del criminal y la reparación a la víctima del daño causado.

¿La prevención importa solo al Estado o a toda la sociedad? Evidentemente concierne a todos. De ahí que no solamente deba tener perspectiva penal general y especial, pues la pena llega siempre tarde; tiene un sesgo individual cuando el problema es social, y convierte en actores protagónicos a las agencias del sistema penal, en desmedro y ocultamiento de la comunidad.

Por otro lado, el alcance de la prevención debe abarcar tres dimensiones o momentos. La prevención primaria, orientada a las reformas sociales de carácter estructural para neutralizar los factores criminógenos; la prevención 
secundaria, dirigida a la manifestación del problema criminal, ya no a su génesis, para lo cual deben planificarse programas de planificación urbana, arquitectónicos, comunicacionales, policiales; y la prevención terciaria, encaminada al penado, para evitar la reincidencia y habitualidad en el crimen, en la que debe proyectarse una verdadera resocialización con base en la educación y el trabajo, así como en el cambio cultural de la sociedad para desterrar la estigmatización.

No olvidemos que una eficaz política criminológica será la que controle razonablemente la criminalidad, no la que pretenda eliminarla, pues esta es consustancial y normal en toda sociedad, dado que ella se basa en el conflicto y no en el consenso. Asimismo, una positiva orientación axiológica de una política criminológica será la que emplee medios legítimos y democráticos con el menor costo social posible en materia de dignidad y derechos humanos. Finalmente, el sentido teleológico de una política criminológica debe ser preventivo a mediano y largo plazo, con intervención protagónica de la sociedad y prestaciones positivas para superar carencias, desigualdades, inestabilidades y conflictos, a fin de redelinear la relación social en orden a términos de igualdad y solidaridad. Además, debe ser sostenida en el tiempo e integrada sectorialmente con un enfoque multidireccional para abarcar todas las variables que interactúan en la aparición del crimen. Por ello, no cabe duda alguna de que la política criminológica en un estado democrático y de derecho debe basarse, primeramente, en el respeto a la dignidad humana y los derechos humanos. En segundo término, debe sustentarse científicamente en la criminología.

Comencemos cada uno de los miembros de la sociedad examinando, reconociendo y analizando los valores y actitudes con los que ejercemos nuestra libertad en la relación que tenemos con los demás, para concienciarnos de que debemos actuar conforme al paradigma ético de la autonomía, como señalan Giusti y Tubino (2007) a fin de reconocer que nuestra libertad solo se afirma mediante el respeto de la libertad de todos. Esto es, sin perjudicar a los demás, de acuerdo al imperativo categórico kantiano y a los caracteres de racionalidad, neutralidad, imparcialidad y deliberación. Como apuntan los reconocidos filósofos nacionales, solo así lograremos construir una sociedad más justa para todos, guiada por un sistema de normas igualitarias de convivencia más que por valores contextualizados, que sustentan más bien un anacrónico paradigma ético del bien común, cuyos caracteres son la injerencia de las emociones, la toma de posición parcial de la primera persona y la referencia a la ética como última razón de fundamentación basada en la tradición comunal.

\section{CONCLUSIONES}

La criminalidad es un fenómeno social natural de etiología multicausal, objeto de la criminología, junto con la persona del infractor, la víctima y el control social. Por ello, para su prevención, neutralización y reducción, debe contarse con la información válida de dicha ciencia a fin de diseñar una política criminológica eficaz.

La política criminológica es el conjunto de medidas integrales y sistémicas que adopta el Estado, según sus características, para enfrentar la criminalidad de un modo organizado a mediano y largo plazo.

La política criminológica de un Estado democrático y de derecho debe respetar la dignidad y los derechos humanos por su propia naturaleza. No debe instrumentalizar a la persona humana para lograr la seguridad integral, ya que esta no es el fin sino el medio para la realización de aquella.

De los sistemas de control social, el penal es el que contiene la mayor fuerza del Estado, razón por la cual debe ser empleado con arreglo a los principios de última ratio, mínima intervención y subsidiaridad.

El derecho penal no debe ser simbólico, es decir, engañoso y falaz, sino eficaz, generador de paz social con un mínimo coste social a fin de lograr el verdadero fin de la norma.

La declaración del estado de emergencia en la Provincia Constitucional del Callao fue una medida innecesaria, carente de racionalidad e ineficaz, que inaugura una nueva modalidad en la particular lucha contra la criminalidad en nuestro país: el uso de normas simbólicas de represión y restricción de derechos fundamentales en perjuicio de la ciudadanía. 
Es necesario un cambio de actitud en la conducción política del Estado respecto al tema de seguridad, que es uno de sus fines esenciales, para que el poder de control sea ejercido de manera democrática en sus fases de definición, asignación y ejecución. Esto cambiará de rumbo el proyecto hegemónico de dominación que se ejerce desde la aparición del Estado moderno en occidente contra los grupos marginales económicamente vulnerables.

El castigo penal al prójimo en las comunidades desiguales, como la nuestra, es refractario al ideal democrático y republicano de nuestra forma de Estado y se mantiene en la errónea idea de que el derecho penal no puede entenderse más allá de la sobrepenalización y la demagogia punitiva; de ahí que toda política estatal tienda a crear las condiciones favorables para la represión y restricción a la persona humana.

La finalidad de castigar el crimen no debe ser vengarse y excluir al criminal, sino reeducarlo y resocializarlo para reintegrarlo a la sociedad. Tal fin implica regenerar nuestros acuerdos sociales, que supone renovar el recíproco entendimiento a través de formas racionales de diálogo y deliberación.

Frente al índice de criminalidad, vemos cómo el Estado está comprometido con la imposición premeditada y posterior de daño y sufrimiento en venganza del ocasionado con la conducta desviada. En su lugar, debería prevenir los comportamientos gravemente dañinos con cambios en las estructuras económicas, sociales y culturales para disminuir la brecha de desigualdad y exclusión en nuestra sociedad, que es uno de los factores criminógenos más recurrentes.

\section{REFERENCIAS BIBLIOGRÁFICAS}

Agamben, Giorgio (2003) Homo sacer. El poder soberano y la nuda vida. Valencia. Pretextos.

García-Pablos de Molina, Antonio (1994). Criminología: una introducción a sus fundamentos teóricos para juristas (2. ${ }^{a}$ edición). Valencia: Tirant to Blanch.

Giusti, Miguel y Tubino, Fidel (2007). El sentido de la ética. En Debates de la Ética Contemporánea. Perú. Fondo Editorial de la Pontificia Universidad Católica del Perú, pp. 13-42.

Habermas, Jürgen (1992). Conocimiento $e$ interés. Madrid: Taurus, p. 259.

Instituto Nacional de Estadística e informática (INEI) (sin fecha). Estadísticas de seguridad ciudadana. Recuperado el 10 de enero de 2017 de: http://www.inei.gob.pe/bibliotecavirtual/boletines/estadisticas-de-seguridadciudadana/2015/1/

Ministerio del Interior ( $\sin$ fecha). Observatorio Nacional de Seguridad Ciudadana. Recuperado el 10 de enero de 2017 de: http://conasec. mininter.gob.pe/obnasec/mdelito.html

Quispe, Alfredo (sin fecha). Régimen de excepción. Recuperado el 16 de diciembre de: http://revistas.pucp.edu.pe/index.php/ derechopucp/article/viewFile/5849/5842, pp. 141-148

Van Dijk, Teun (1992). El análisis crítico del discurso. Anthropos N. ${ }^{\circ} 186$, septiembreoctubre, p. 26. 